Check for updates

1 University of Manchester

2 University of Nottingham

3 De Montfort University

Cite this as: BMJ 2021;375:n3087

http://dx.doi.org/10.1136/bmj.n3087

Published: 14 December 2021

\section{Protection from covid-19 at work: health and safety law is fit for purpose}

\section{Shortcomings in protection from contracting covid at work arise from legislation being ignored, argue these authors}

\author{
Raymond M. Agius, ${ }^{1}$ Diana Kloss, ${ }^{1}$ Denise Kendrick, ${ }^{2}$ Marcia Stewart, ${ }^{3}$ John FR Robertson ${ }^{2}$
}

The 2020 Coronavirus Act and ensuing secondary legislation, as well as official government coronavirus guidance, have provided some limited protection from covid-19 for workers such as by temporarily implementing work from home orders. ${ }^{1}$ By contrast, the health of employees and others in workplaces remains potentially well protected by laws dating back at least as far as the 1974 Health and Safety etc at Work Act. ${ }^{2-4}$ This mandates that employers have duties to ensure both the health of their employees and of others affected by the conduct of their undertakings, such as patients, students, and site visitors.

Regrettably, government departments, notably the Department of Health and Social Care and the Department for Education, fell short in emphasising the obligations of employers to protect their employees health during the covid-19 pandemic. The Omicron variant has increased transmissibility and likely partial vaccine resistance, and therefore especially warrants appropriate safeguards for employees, particularly front line healthcare and social care workers who will be extremely vulnerable to exposure in the impending outbreak. ${ }^{5}$

The most recent guidance on infection prevention and control (IPC), published by the UK Health Security Agency, goes further than earlier iterations in advising compliance with health and safety legislation in protecting healthcare workers. ${ }^{6}$ However, it is still flawed, for instance, in recommending less respiratory protection for healthcare workers routinely exposed to patients infected with covid-19, which it considers both droplet transmissible and airborne, than for tuberculosis which it deems solely airborne.

The law imposes the duty on all employers to undertake a "suitable and sufficient risk assessment" proportionate to the risk arising from exposure at work and appropriate to the nature of the work, and this obligation overrides IPC guidance. ${ }^{7}$ Evidence has grown overwhelmingly regarding the airborne viral exposure of healthcare workers and the corresponding effectiveness of appropriate respiratory protective equipment in controlling this risk. ${ }^{910}$ This has been accompanied by an increasing number of NHS Trusts which have recognised this need as well as the practical feasibility of deploying respirators as respiratory protective equipment to protect healthcare workers in the routine care of patients with covid-19 or at significant risk of carrying it. ${ }^{11}$ Thus the law courts would be justified in taking the view that these pacesetting NHS Trusts have satisfied the "reasonably practicable" legal test and would "ensure the health at work of all employees" 11 This would contrast with the weaker UKHSA guidance. ${ }^{6}$ The Health and Safety Executive (HSE) has been relatively silent with regards to the protection of frontline healthcare workers from covid-19 and, without any evidence, had simply endorsed Public Health England's guidance as "effective control measures." 12 Therefore these pacesetting NHS Trusts, and not UKHSA nor HSE, have effectively been setting the legal standard for protection mandated by the paramount primary legislation. ${ }^{4}$ Hence this protection (e.g. respiratory protective equipment such as $\mathrm{FFP}_{3}$ respirators to protect healthcare workers in the routine care of patients potentially with covid-19) would be what all NHS Trusts ought to provide, in order to comply with their legal obligations.

In addition to the legal obligations to assess and mitigate risks to all employees who are vulnerable to ill health by virtue of collective classes of exposure, the law imposes obligations to safeguard individuals. Thus, risk assessments should also address the protection of groups of individuals who are susceptible to a higher risk to health because of factors such as gender, age, comorbidity, and ethnicity. ${ }^{13}$ The Equality Act imposes obligations on employers to take into account individual disabilities: for instance, a reasonable adjustment might entail a "clinically extremely vulnerable individual" continuing to work from home. ${ }^{14}$ Such legal obligations antedate and will persist independently of any coronavirus regulations. ${ }^{1}$

Concerns about the application, and enforcement, of the law are as relevant now as at the start of the pandemic. In spite of the advantages afforded by vaccination, breakthrough significant infections have been recognised, and this risk is likely to worsen with new variants such as Omicron. ${ }^{515} 16$ Many workers rightly concerned in spite of Government regulations and guidance. If coronavirus regulations do not explicitly mandate certain precautions, these measures (for example wearing masks in classrooms or catering establishments) can and must be enforced locally if they arise from an appropriate risk assessment conducted in consultation with employees as required by law. ${ }^{17} 18$

The Management of Health and Safety at Work Regulations impose a duty on employers to give comprehensible and relevant information to employees of risks to their health and safety identified and employers, from healthcare to education, remain 
by the risk assessment and preventive and protective measures. ${ }^{3}$ In the case of public bodies, such as NHS hospitals and most schools, the public has a right to see such risk assessments by virtue of the Freedom of Information Act. ${ }^{19}$

Most of the serious shortcomings in protection of workers and others from contracting covid at work arise from the authorities and many employers ignoring legislation and precautionary principles as well as inadequate enforcement, rather than from the existing law being unfit for purpose.

Competing interests: Raymond Agius is a member of Council of the British Medical Association (BMA), acting chair of the BMA Occupational Medicine Committee and a member of the Industrial Injuries Advisory Council but is writing in a personal capacity. None further declared.

Provenance and peer review: not commissioned, not peer reviewed

1 HMSO. Coronavirus Act UK. Public General Acts 2020 c.7. https://www.legislation.gov.uk/ukpga/2020/7/enacted

2 HMSO. The Control of Substances Hazardous to Health Regulations 2002. UK Statutory Instruments. 2002 No. 2677 https://www.legislation.gov.uk/uksi/2002/2677/made

3 HMSO. The Management of Health and Safety at Work Regulations 1999. UK Statutory Instruments1999 No. 3242 Management of H\&S at Work Regulations 1999 https://www.legislation.gov.uk/uksi/1999/3242/made

4 HMSO. Health and Safety at Work etc. Act. UK Public General Acts 1974 c.37 https://www.legislation.gov.uk/ukpga/1974/37

5 Torjesen I. Covid-19: Omicron may be more transmissible than other variants and partly resistant to existing vaccines, scientists fear. BM/2021;375:n2943.

doi: 10.1136/bmj.n2943. pmid: 34845008

6 UK Health Security Agency. Infection prevention and control for seasonal respiratory infections in health and care settings (including SARS-CoV-2) for winter 2021 to 2022. Guidance. Updated 23 November 2021 https:/www.gov.uk/government/publications/wuhan-novel-coronavirus-infection-prevention-and-control/covid-19-guidance-for-maintaining-services-within-health-andcare-settings-infection-prevention-and-control-recommendations

7 Health and Safety Executive. What the law says on assessing risks. Last accessed 22 November 2021. https://www.hse.gov.uk/managing/delivering/do/profiling/the-law.htm

8 Health Service Journal (HSJ) Bampton K. Agius RM, Peters C, Gallagher R, Jones B. When it comes to staff safety during the pandemic, the buck stops with chief executives. 24 August 2021. https://www.hsj.co.uk/policy-and-regulation/when-it-comes-to-staff-safety-during-the-pandemicthe-buck-stops-with-chief-executives/7030773.article

9 Ferris M, Ferris R, Workman C, et al. FFP3 respirators protect healthcare workers against infection with SARS-CoV-2. https://www.authorea.com/users/421653/articles/527590-ffp3-respiratorsprotect-healthcare-workers-against-infection-with-sars-cov-2?commit=e567e67501cd6ee0dd1a6e8e4acdf2c4fd70e0ec

10 Lawton T, Butler M, Peters C, et al. Use of airborne precautions for covid-19 in healthcare settings. BMJ Opinion, 28 Jun 2021. https://blogs.bmj.com/bmj/2021/06/28/use-of-airborne-precautionsfor-covid-19-in-healthcare-settings/

11 Lawton T, Butler M, Peters C. Airborne protection for staff is associated with reduced hospital-acquired COVID-19 in English NHS Trusts. J Hosp Infect2021;S0195-6701(21)00427-8. doi: 10.1016/j.jhin.2021.11.018. pmid: 34861313

12 Agius RM, Robertson JFR, Kendrick D, Sewell HF, Stewart M, McKee M. Covid-19 in the workplace. BMJ 2020;370:m3577. https://www.bmj.com/content/370/bmj.m3577.full. doi: 10.1136/bmj.m3577 pmid: 32958470

13 Khunti K, Griffiths A, Majeed A, Nagpaul C, Rao M. Assessing risk for healthcare workers during the covid-19 pandemic. BMJ2021;372:n602. doi: 10.1136/bmj.n602. pmid: 33722904

14 Kloss D. Occupational Health Law. 6th ed. Wiley Blackwell, 2020: 300doi: 10.1002/9781118936221.

15 Sewell HF, Agius RM, Kendrick D, Stewart M. Covid-19 vaccines: delivering protective immunity. BMJ 2020;371:m4838. https://bmj.com/cgi/content/full/bmj.m4838. doi: 10.1136/bmj.m4838 pmid: 33334862

16 Bergwerk M, Gonen T, Lustig Y, etal. Covid-19 Breakthrough Infections in Vaccinated Health Care Workers. NEngl/ Med2021;385:1474-84. https://www.nejm.org/doi/full/10.1056/NEJMoa2109072. doi: 10.1056/NEJMoa2109072 pmid: 34320281

17 Agius RM, Hughes LT, Kendrick D, Robertson JFR, Stewart M. Assessing risk for healthcare workers during the pandemic: don't forget workplace safety committees or airborne transmission. BMJ2021;373. doi: 10.1136/bmj.n950. pmid: 33849911

18 HMSO. The Safety Representatives and Safety Committees Regulations 1977. UK Statutory Instruments1977 No. 500 https://www.legislation.gov.uk/uksi/1977/500/made

19 HMSO. Freedom of Information Act 2000. UK Public General Acts2000 c. 36 https://www.legislation.gov.uk/ukpga/2000/36

20 HMSO. Employment Rights Act 1996. UK Public General Acts1996 c. 18 https://www.legislation.gov.uk/ukpga/1996/18 